be well explained through the change of weight fraction of fine particles near the bed surface.

$\begin{array}{llr}\text { Nomenclature } & \\ d_{p} & =\text { particle diameter } & {[\mathrm{mm}]} \\ \bar{d}_{p} & =\text { mean particle diameter } & {[\mathrm{mm}]} \\ E & =\text { elutriation rate } & {\left[\mathrm{kg} / \mathrm{m}^{2} \mathrm{~s}\right]} \\ h & =\text { height from gas distributor } & {[\mathrm{m}]} \\ H_{o} & =\text { static bed height } & {[\mathrm{m}]} \\ U & =\text { superficial gas velocity } & {[\mathrm{m} / \mathrm{s}]} \\ U_{m f} & =\text { minimum fluidisation velocity of } & \\ \bar{U}_{m f} & & \text { monocomponent particle } \\ & =\text { minimum fluidisation velocity of binary } & {[\mathrm{m} / \mathrm{s}]} \\ U_{t} & & \\ X & =\text { terminal velocity } & {[\mathrm{m} / \mathrm{s}]} \\ \bar{X} & =\text { weight fraction of fine particles } & {[\mathrm{m} / \mathrm{s}]} \\ Z & =\text { bulk weight fraction of fine particles } & {[-]} \\ & =\text { dimensionless bed height } & {[-]} \\ \varepsilon_{m f} & = & {[-]} \\ \rho_{m f} & =\text { voidage of incipiently fiuidised bed } \\ \rho_{p} & =\text { particle density of incipiently fluidised bed }\left[\mathrm{kg} / \mathrm{m}^{3}\right] \\ & & {\left[\mathrm{kg} / \mathrm{m}^{3}\right]}\end{array}$

\section{Literature Cited}

1) Cheung, L. Y.-L., A. W. Nienow and P. N. Rowe: Chem. Eng. Sci., 29, 1301 (1974).

2) Chiba, S., T. Chiba, A. W. Nienow and H. Kobayashi: Chem. Eng. Sci., 29, 255 (1979).

3) Geldart, D. and D. J. Pope: Preprints of AIChE 71st An. Meeting, Miami Beach (1978).

4) Geldart, D., J. Cullian, S. Georghides, D. Gilvray and D. J. Pope: Trans. Inst. Chem. Eng., 57, 269 (1979).
5) Guha, S. K., A. Kumer and P. Sen Gupta: Can. J. Chem. Eng., 50, 602 (1980).

6) Horio, M., A. Taki, Y. S. Hsieh and I. Muchi: "Fluidization," ed. by J. R. Grace and J. M. Matson, p. 509, Plenum Press, New York (1980).

7) Kunii, D. and O. Levenspiel: "Fluidization Engineering," $\mathrm{Ch}$. 10 , John Wiley \& Sons. Inc. (1969).

8) Leva, M. and C. Y. Wen: "Fluidization," ed. by J. F. Davidson and D. H. Harrison, Ch. 14, Academic Press (1971).

9) Lin, L., J. T. Sears and C. Y. Wen: Powder Technol., 27, 105 (1980).

10) Matsuno, Y., H. Kage, T. Nagamitsu, K. Higashitani, Y. Ideue and H. Yamaguchi: "Fluidization," ed. by M. Kwauk and D. Kunii, p. 47, Science Press (1982).

11) Morooka, S., K. Kawazuishi and Y. Kato: Powder Technol., 26, 75 (1980).

12) Nienow, A. W. and T. Chiba: I. Chem. Eng., Symp. Ser., No. 65 , p. S2/F/1 (1981).

13) Sycheva, T. N. and E. V. Donat: Int. Chem. Eng., 10, 172 (1970).

14) Sycheva, T. N. and E. V. Donat: Int. Chem. Eng., 15, 346 (1975).

15) Tanaka, I. and H. Shinohara: J. Chem. Eng. Japan, 5, 27 (1972).

16) Tanaka, I., H. Shinohara, H. Hirosue and Y. Tanaka: J. Chem. Eng. Japan, 5, 51 (1972).

17) Urabe, S., I. Hiraki, K. Yoshida and D. Kunii: Kagaku Kögaku, 29, 19 (1965).

18) Zenz, F. A. and D. F. Othmer: "Fluidisation and FluidParticle Systems," Ch. 12, Reinhold, New York (1960).

(Presented at the 47th Annual Meeting of The Society of Chemical Engineers, Japan, at Tokyo, March 29, 1982.)

\title{
NUMERICAL METHOD FOR SOLVING STEADY THREE-DIMENSIONAL HEAT CONDUCTION PROBLEM IN SECTOR COLUMN
}

\author{
IKUHO YAMADA, SETSURo HIRAOKA, HAJIME NAKAMURA, \\ SHIGEKATSU MORI, YOSHIHIRO MIZUTANI AND SATOSHI MATSUI \\ Department of Industrial Chemistry, Nagoya Institute of Technology, Nagoya 466
}

Generally, the partial differential equation, which describes the three-dimensional steady heat conduction problem by use of the cylindrical coordinate system, is given by the following equation.

$$
\frac{\partial^{2} T}{\partial z^{2}}+\frac{\partial^{2} T}{\partial r^{2}}+\frac{1}{r} \frac{\partial T}{\partial r}+\frac{1}{r^{2}} \frac{\partial^{2} T}{\partial \theta^{2}}=0
$$

where the thermal conductivity is assumed to be constant. Using the relationship $y \equiv \ln r$, Eq. (1) can be transformed into the following equation.

Received April 19, 1982. Correspondence concerning this article should be addressed to I. Yamada. H. Nakamura is at Dept. of Mech. Eng., Daido Inst. of Tech. Nagoya 457.

$$
e^{2 y} \frac{\partial^{2} T}{\partial z^{2}}+\frac{\partial^{2} T}{\partial y^{2}}+\frac{\partial^{2} T}{\partial \theta^{2}}=0
$$

Then, the following 7-point finite difference equations (F.D.E. hereafter) for Eqs. ( $\overline{1})$ and (2) by means of the computational molecules, i.e.,

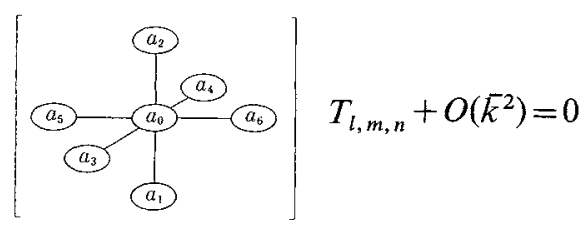




$$
\begin{aligned}
& a_{0}=-2\left(1+\bar{p}^{2}+\frac{s^{2}}{r^{2}}\right) \quad b_{0}=-2\left(e^{2 y}+p^{2}+q^{2}\right) \\
& a_{1}=a_{2}=1 \quad b_{1}=b_{2}=e^{2 y} \\
& a_{3}=a_{4}=\frac{s^{2}}{r^{2}} \quad b_{3}=b_{4}=q^{2} \\
& a_{5}=\bar{p}^{2}-\frac{h \bar{p}}{2 r} \quad b_{5}=b_{6}=p^{2} \\
& a_{6}=\bar{p}^{2}+\frac{h \bar{p}}{2 r} \\
& c_{0}=-\frac{4}{3}\left(1+\bar{p}^{2}+\frac{q^{2}}{r^{2}}\right)+\frac{k^{2}}{6 r^{2}}+\frac{h^{2}}{3 r^{2}}-\frac{k^{2} q^{2}}{2 r^{4}} \\
& d_{0}=-\frac{1}{3}\left\{e^{2 y}\left(4+2 k^{2}\right)+\left(4-\frac{k^{2}}{3}\right)\left(p^{2}+q^{2}\right)\right\} \\
& c_{1}=c_{2}=\frac{2}{3}-\frac{1}{6}\left(\bar{p}^{2}+\frac{q^{2}}{r^{2}}\right)-\frac{k^{2}}{12 r^{2}} \\
& c_{3}=c_{4}=\frac{2 q^{2}}{3 r^{2}}-\frac{1}{6}\left(1+\bar{p}^{2}\right)+\frac{q^{2} k^{2}}{4 r^{4}} \\
& d_{1}=d_{2}=\frac{1}{3}\left\{e^{2 y}\left(2+k^{2}\right)-\frac{1}{2}\left(1+\frac{k^{2}}{3}\right)\left(p^{2}+q^{2}\right)\right\} \\
& d_{3}=d_{4}=\left(\frac{2}{3}-\frac{k^{2}}{18}\right) q^{2}-\frac{1}{6}\left(e^{2 y}+p^{2}\right) \\
& c_{5}=\frac{2}{3} \bar{p}^{2}-\frac{1}{6}\left(1+\frac{q^{2}}{r^{2}}+\frac{h^{2}}{r^{2}}\right)-\frac{\bar{p} h}{2 r}+\frac{1}{12 r}\left(2 \bar{p} h+\bar{k}-\frac{3 q^{2} \bar{k}}{r^{2}}\right) \\
& d_{5}=\frac{e^{2 y}}{6}(2 k-1)+\left(\frac{2}{3}-\frac{k^{2}}{18}\right) p^{2}-\frac{1}{6} q^{2} \\
& c_{6}=\frac{2}{3} \bar{p}^{2}-\frac{1}{6}\left(1+\frac{q^{2}}{r^{2}}+\frac{h^{2}}{r^{2}}\right)+\frac{\bar{p} h}{2 r}-\frac{1}{12 r}\left(2 \bar{p} h+\bar{k}-\frac{3 q^{2} \bar{k}}{r^{2}}\right) \\
& d_{6}=\frac{e^{2 y}}{6}(-2 k-1)+\left(\frac{2}{3}-\frac{k^{2}}{18}\right) p^{2}-\frac{1}{6} q^{2} \\
& c_{7}=c_{8}=\frac{1}{12}\left(\bar{p}^{2}+\frac{q^{2}}{r^{2}}\right)-\frac{1}{24 r}\left(\bar{p} h-\frac{3 q^{2} \bar{k}}{r^{2}}\right) \\
& c_{9}=c_{10}=\frac{1}{12}\left(\bar{p}^{2}+\frac{q^{2}}{r^{2}}\right)-\frac{1}{24 r}\left(\bar{p} h-\frac{3 q^{2} \bar{k}}{r^{2}}\right) \\
& c_{11}=c_{12}=\frac{1}{12}\left(1+\bar{p}^{2}\right)-\frac{1}{24 r}(\bar{p} h+\bar{k}) \\
& c_{13}=c_{14}=\frac{1}{12}\left(1+\bar{p}^{2}\right)+\frac{1}{24 r}(\bar{p} h+k) \\
& c_{15}=c_{16}=c_{17}=c_{18}=\frac{1}{12}\left(1+\frac{q^{2}}{r^{2}}\right) \\
& d_{7}=d_{8}=d_{9}=d_{10}=\frac{1}{12}\left(p^{2}+q^{2}\right) \\
& d_{11}=d_{12}=\frac{1}{12}\left\{e^{2 y}(1-2 k)+\left(1+\frac{k^{2}}{3}\right) p^{2}\right\} \\
& d_{13}=d_{14}=\frac{1}{12}\left\{e^{2 y}(1+2 k)+\left(1+\frac{k^{2}}{3}\right) p^{2}\right\} \\
& d_{15}=d_{16}=d_{17}=d_{18}=\frac{1}{12}\left\{e^{2 y}+\left(1+\frac{k^{2}}{3}\right) q^{2}\right\} \\
& \text { where } \quad \bar{p} \equiv \frac{h}{\bar{k}}, \quad p \equiv \frac{h}{k}, \quad \text { and } \quad q \equiv \frac{h}{s}
\end{aligned}
$$

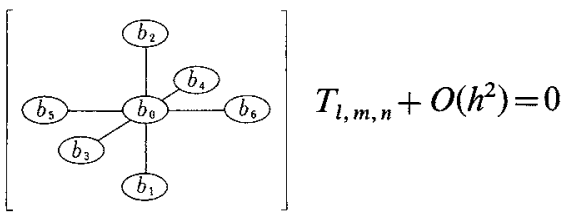

have frequently been used to obtain the approximated temperature profile in a sector column under various boundary conditions, where $a_{0}-a_{6}$ and $b_{0}-b_{6}$ in the molecules are listed in Table 1 and the relationship between the direction of coordinates and the position of molecules is presented in Fig. 1.

The purpose of this paper is to compare 19-point F.D.E. with 7-point F.D.E. The 19-point F.D.E. are

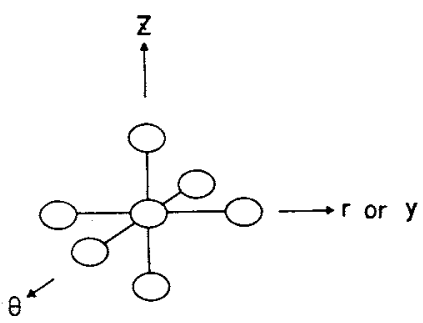

Fig. 1. Relationship between direction of coordinates and position of molecules.

derived by a derivation process ${ }^{1,2)}$ similar to that for Greenspan's 9-point finite difference equation for the two-dimensional orthogonal coordinate system. 


\section{Derivation of 19-point F.D.E.}

Using the central difference operator $\delta$, Eqs. (1) and (2) can be written by the following equations.

For Eq. (1)

$$
\begin{aligned}
& {\left[\left(\delta_{z}^{2}-\frac{1}{12} \delta_{z}^{4}+\frac{1}{90} \delta_{z}^{6} \cdots\right)\right.} \\
& \quad+\bar{p}^{2}\left(\delta_{r}^{2}-\frac{1}{12} \delta_{r}^{4}+\frac{1}{90} \delta_{r}^{6} \cdots\right) \\
& \quad+\frac{\bar{p} h}{r} \mu\left(\delta_{r}-\frac{1}{6} \delta_{r}^{3}+\frac{1}{60} \delta_{r}^{5} \cdots\right) \\
& \left.\quad+\frac{q^{2}}{r^{2}}\left(\delta_{\theta}^{2}-\frac{1}{12} \delta_{\theta}^{4}+\frac{1}{90} \delta_{\theta}^{6} \cdots\right)\right] T_{l, m, n}=0
\end{aligned}
$$

For Eq. (2)

$$
\begin{aligned}
& {\left[e^{2 y}\left(\delta_{z}^{2}-\frac{1}{12} \delta_{z}^{4}+\frac{1}{90} \delta_{z}^{6} \cdots\right)\right.} \\
& \quad+p^{2}\left(\delta_{y}^{2}-\frac{1}{12} \delta_{y}^{4}+\frac{1}{90} \delta_{z}^{6} \cdots\right) \\
& \left.\quad+q^{2}\left(\delta_{\theta}^{2}-\frac{1}{12} \delta_{\theta}^{4}+\frac{1}{90} \delta_{\theta}^{6} \cdots\right)\right] T_{l, m, n}=0
\end{aligned}
$$

When only the first terms in parentheses in Eqs. (5) and (6) are retained, Eqs. (5) and (6) are reduced to Eqs. (3) and (4) respectively. To obtain more accurate finite difference equations for Eqs. (1) and (2), the second terms in parentheses, $\mu \delta_{r}^{3}, \delta_{z}^{4}, \delta_{r}^{4}$ and $\delta_{z}^{4}$ for Eq. (5) and $\delta_{z}^{4}, \delta_{\theta}^{4}$ and $\delta_{\theta}^{4}$ for Eq. (6), should be considered. However, computations of higher-order differences at points adjacent to the boundary are very difficult. To avoid this computational difficulty the following procedure is adopted here.

For Eq. (1): Partially differentiating Eq. (1) once with respect to $r$ and twice with respect to $z, r$ and $\theta$ respectively, one can finally obtain the following relationships.

$$
\begin{aligned}
\mu \delta_{r}^{3}= & -\frac{1}{r} \bar{p}^{-2} \bar{k} \delta_{z}^{2}-\frac{2 k}{r} \delta_{r}^{2}+\frac{1}{r^{3}} q^{2} \bar{p}^{-2} \bar{k} \delta_{\theta}^{2} \\
& -\frac{1}{r^{2}} \bar{p}^{-2} q^{2} \mu \delta_{r} \delta_{\theta}^{2}-\bar{p}^{-2} \mu \delta_{r} \delta_{z}^{2} \\
\delta_{z}^{4}= & -\bar{p}^{2} \delta_{z}^{2} \delta_{r}^{2}-\frac{1}{r} \bar{p} h \delta_{z}^{2} \mu \delta_{r}-\frac{1}{r^{2}} q^{2} \delta_{z}^{2} \delta_{\theta}^{2} \\
\delta_{r}^{4}= & \frac{3}{r^{2}} \bar{p}^{-2} \bar{k}^{2} \delta_{z}^{2}+\frac{6}{r^{2}} \bar{k}^{2} \delta_{r}^{2}-\frac{5}{r^{4}} p^{-2} q^{2} \bar{k}^{2} \delta_{\theta}^{2} \\
& +\frac{5}{r^{3}} \bar{p}^{-2} q^{2} \bar{k} \mu \delta_{r} \delta_{\theta}^{2}-\frac{1}{r^{2}} \bar{p}^{-2} q^{2} \delta_{r}^{2} \delta_{\theta}^{2} \\
& \quad \bar{p}^{-2} \delta_{r}^{2} \delta_{z}^{2}+\frac{1}{r} p^{-2} k \mu \delta_{r} \delta_{z}^{2} \\
\delta_{\theta}^{4}=- & r^{2} q^{-2} \delta_{z}^{2} \delta_{\theta}^{2}-r^{2} p^{2} q^{-2} \delta_{r}^{2} \delta_{\theta}^{2}-r p q^{-1} s \delta_{\theta}^{2} \mu \delta_{r}(
\end{aligned}
$$

Substitution of Eqs. (7)-(10) into Eq. (5) gives the following 19-point finite difference equation, where the values of $c_{0}-c_{18}$ are listed in Table 1.

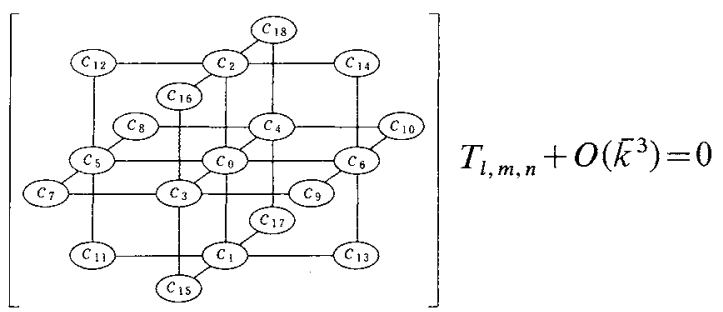

For Eq. (2): Partially differentiating Eq. (2) twice with respect to $z, y$ and $\theta$ respectively, the following relationships can be obtained.

$$
\begin{aligned}
\delta_{z}^{4}= & -e^{-2 y}\left(p^{2} \delta_{z}^{2} \delta_{y}^{2}+q^{2} \delta_{z}^{2} \delta_{\theta}^{2}\right) \\
\delta_{y}^{4}= & -4 e^{2 y} p^{-2} k^{2} \delta_{z}^{2}-4 e^{2 y} p^{-2} k \delta_{z}^{2} \mu \delta_{y}-e^{2 y} p^{-2} \delta_{z}^{2} \delta_{y}^{2} \\
& -p^{-2} q^{2} \delta_{y}^{2} \delta_{\theta}^{2}-\frac{1}{3}\left(k^{2} \delta_{z}^{2} \delta_{y}^{2}+k^{2} p^{-2} q^{2} \delta_{z}^{2} \delta_{\theta}^{2}\right) \\
\delta_{\theta}^{4}= & -e^{2 y} q^{-2} \delta_{z}^{2} \delta_{\theta}^{2}-p^{2} q^{-2} \delta_{y}^{2} \delta_{\theta}^{2}
\end{aligned}
$$

Substitution of Eqs. (12)-(14) into Eq. (6) gives the following 19-point finite difference equation, where the values of $d_{0}-d_{18}$ are also listed in Table 1 .

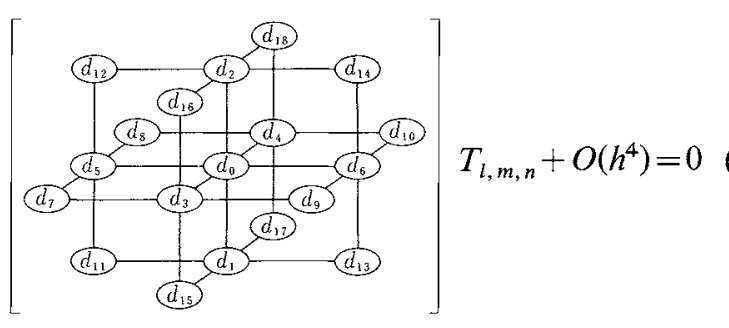

\section{Discussion and Conclusion}

To demonstrate the superiority of Eqs. (11) and (15), sample calculations are illustrated for the steady heat conduction problem in a sector column with the shape and boundary conditions shown in Fig .2. Fortunately, in this problem the analytical solution is given by the following equation.

$$
\begin{aligned}
T=\sum_{m^{\prime}=1}^{\infty} & \sum_{n^{\prime}=1}^{\infty} \frac{4\left\{1-(-1)^{m^{\prime}}\right\}\left\{1-(-1)^{n^{\prime}}\right\}}{m^{\prime} n^{\prime} \pi^{2}} \frac{F\left(m^{\prime}, n^{\prime}, r\right)}{F\left(m^{\prime}, n^{\prime}, r_{i}\right)} \\
& \times \sin n^{\prime} \pi z \sin m^{\prime} \theta
\end{aligned}
$$

where

$$
\begin{gathered}
F\left(m^{\prime}, n^{\prime}, r_{j}\right)-I_{m^{\prime}}\left(n^{\prime} \pi r\right) K_{m}{ }^{\prime}\left(n^{\prime} \pi r_{0}\right)-K_{m^{\prime}}\left(n^{\prime} \pi r\right) I_{m^{\prime}}\left(n^{\prime} \pi r_{i}\right) \\
(j=i, 0)
\end{gathered}
$$

The numerical calculation was carried out by using the Gauss-Seidel algorithm for the various number of divisions $n$ which was taken to be $n \times n \times n$ in the $z, r$ and $\theta$-directions, where the initial values used were $T_{l, m, n}=0$ for all lattice points, and the convergence criterion was $\left|\stackrel{v}{T}_{l, m, n}-\stackrel{v-1}{T_{l, m, n}}\right|_{\max } \leq 10^{-6}$. Moreover, the temperature $T_{B}$ at the boundaries of $(z, 0.5,0)$ and $(z, 0.5, \pi)$, which provides the minimum deviation 
Table 2. Radial distribution of dimensionless temperature at $\theta=\pi / 5, z=0.4$ in semisector column shown in Fig. 2

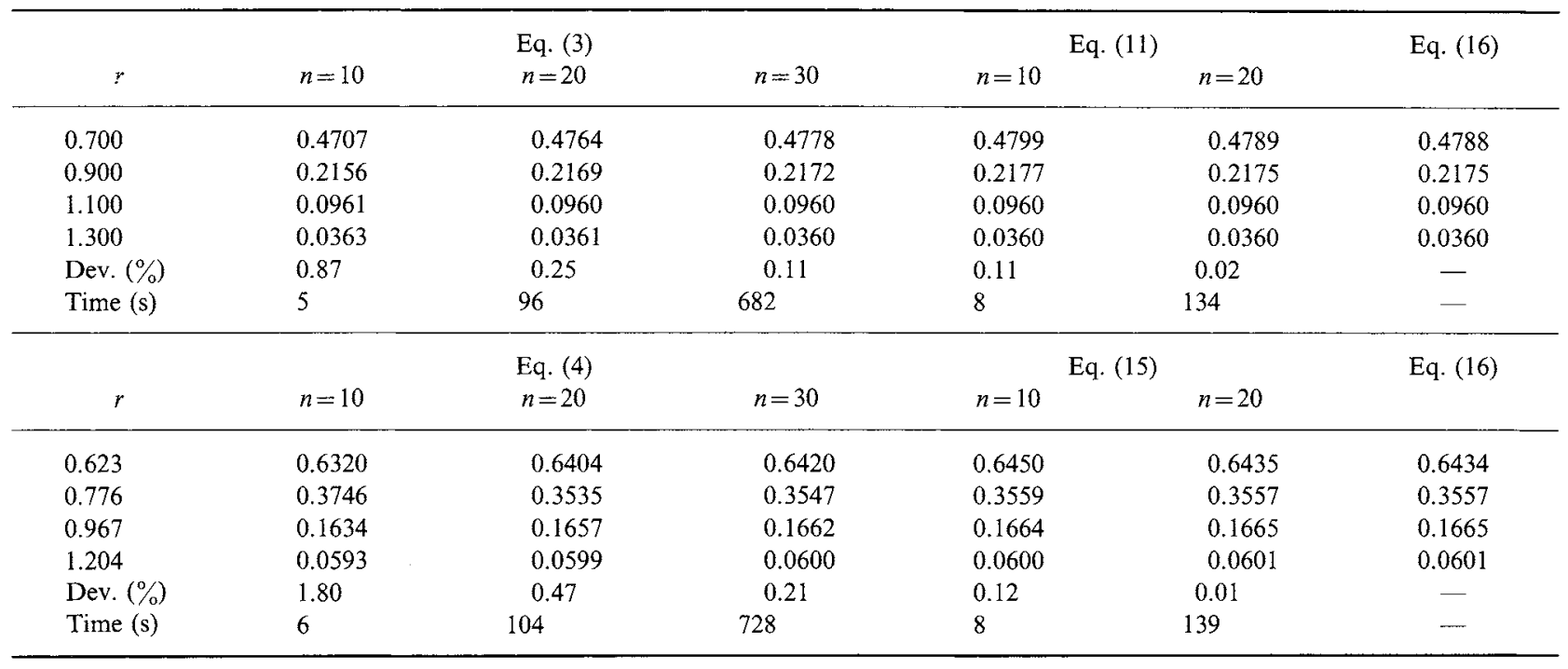

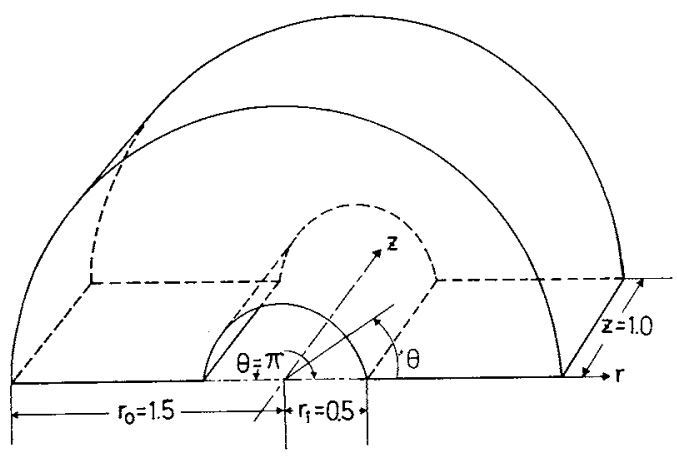

Fig. 2. Shape of sector column for numerical example where $T=1$ for the surface of $r_{i}=0.5$ and $T=0$ for the other surfaces.

from the analytical solution obtained from Eq. (16) was expressed by the following equation.

$$
T_{B}=\frac{1}{1+\rho^{2}}
$$

where $\rho$ denotes any of the ratios of grid spacing $k / h$, $\bar{k} / h$ or $s / h$.

The values of dimensionless temperature for $r$ direction at $z=0.4, \theta=\pi / 5$ obtained by Eqs. (3), (4), (11), (15) and (16) are shown in Table 2. Additionally, mean value of deviation from Eq. (16) and C.P.U. time with M-170 (HITACHI) are also shown in this table. It is found that the results of Eqs. (11) and (15) for $n=20$ are very accurate. On the other hand, though the deviation of $n=30$ in Eq. (3) is equal to that of $n=10$ in Eq. (11), the C.P.U. time required for the former is observed to be about 85 times as long as for the latter.

Therefore, the superiority of the present 19-point F.D.E. to the 7-point F.D.E. is clear.

\begin{tabular}{|c|c|c|}
\hline \multicolumn{3}{|c|}{ Nomenclature } \\
\hline$a_{j}, b_{j}$ & $\begin{array}{l}=\text { elements of computational molecule in } \\
\text { Eqs. (3) and (11) }\end{array}$ & {$[-]$} \\
\hline$h$ & $=$ grid spacing for $z$-direction & {$[-]$} \\
\hline$I_{m}(x)$ & $\begin{array}{l}=\text { modified Bessel function of 1st kind of } \\
\text { order } m\end{array}$ & {$[-]$} \\
\hline$K_{m}(x)$ & $\begin{array}{l}=\text { modified Bessel function of } 2 \text { nd kind of } \\
\text { order } m\end{array}$ & {$[-]$} \\
\hline$k$ & $=$ grid spacing for $y$-direction & {$[-]$} \\
\hline $\bar{k}$ & $=$ grid spacing for $r$-direction & {$[-]$} \\
\hline$n$ & $=$ number of divisions in $z, r$ and $\theta$-directions & {$[-]$} \\
\hline$O()$ & $=$ order of truncation error in F.D.E. & {$[-]$} \\
\hline$p$ & $=$ defined by $h / k$ & {$[-]$} \\
\hline $\bar{p}$ & $=$ defined by $h / \bar{k}$ & {$[-]$} \\
\hline$q$ & $=$ defined by $h / s$ & {$[-]$} \\
\hline$r$ & $=$ dimensionless distance for $r$-direction & {$[-]$} \\
\hline$s$ & $=$ grid spacing for $\theta$-direction & {$[-]$} \\
\hline$T$ & $=$ dimensionless temperature & {$[-]$} \\
\hline$y$ & $=$ defined by $\ln r$ & {$[-]$} \\
\hline$z$ & $=$ dimensionless distance for $z$-direction & {$[-]$} \\
\hline$\delta$ & $=$ central-difference operator & {$[-]$} \\
\hline$\theta$ & $=$ dimensionless distance for angle & {$[-]$} \\
\hline$\mu$ & $=$ average operator & {$[-]$} \\
\hline
\end{tabular}

〈Subscripts〉

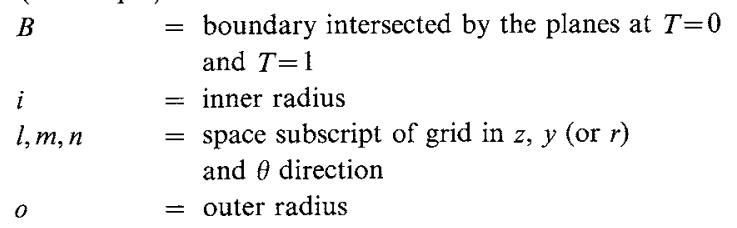

\section{Literature Cited}

1) Greenspan, D.: J. Franklin Inst., 263, 425 (1957).

2) Lapidus, L.: "Digital Computation for Chemical Engineers," p. 143, McGraw-Hill (1962). 